\title{
A Case of SF3B1-Positive Myelodysplastic/Myeloproliferative Neoplasm with Ring Sideroblasts and Thrombocytosis
}

\author{
Halka (Ring) Sideroblast ve Trombositozu Olan SF3B1-Pozitif Myelodisplastik/ \\ Myeloproliferati Neoplazm Olgusu
}

(D) Alejandro Lazo-Langner1,2, (D) Bekim Sadikovic 3

${ }^{1}$ Western University, Schulich School of Medicine, Department of Medicine, London, Ontario, Canada

${ }^{2}$ Western University, Schulich School of Medicine, Department of Epidemiology and Biostatistics, London, Ontario, Canada

${ }^{3}$ Western University, Schulich School of Medicine, Department of Pathology and Laboratory Medicine, London, Ontario, Canada

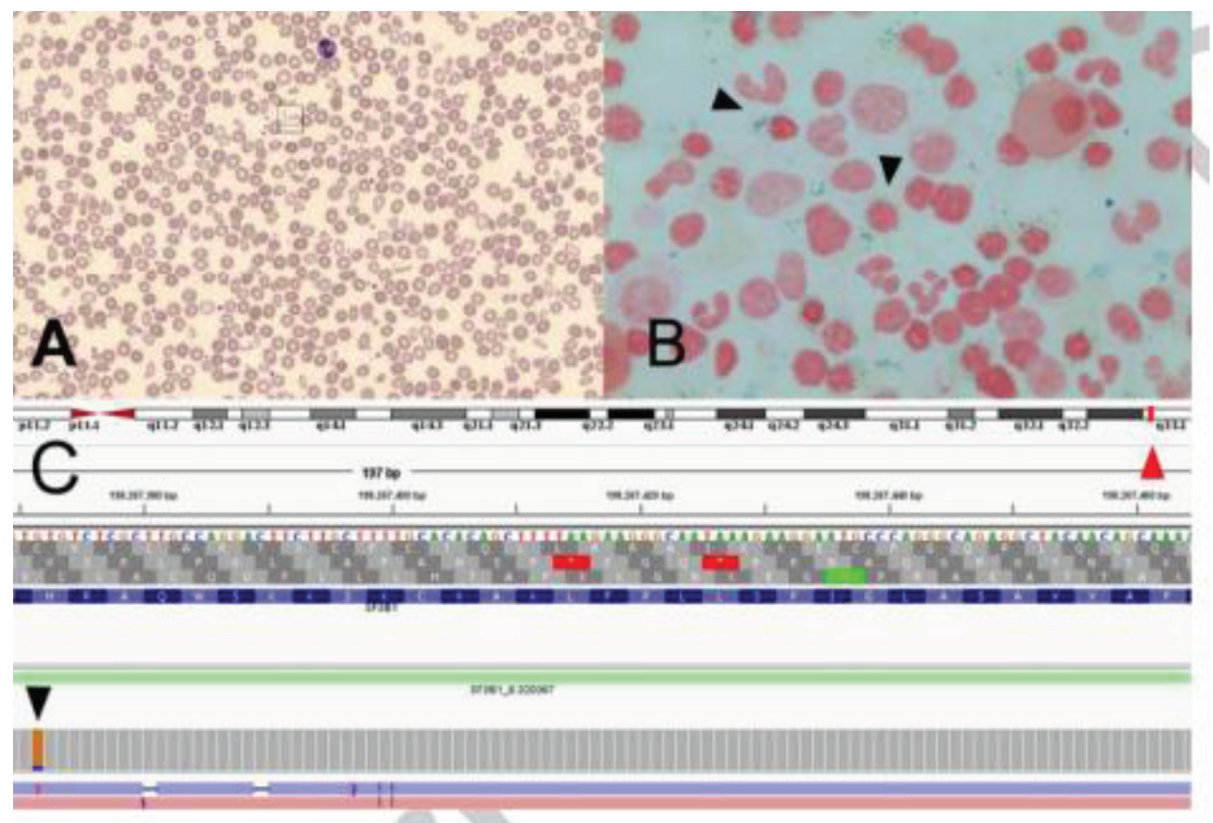

Figure 1. A) Peripheral blood smear (Wright's stain, 40x) showing marked anisopoikilocytosis. B) Bone marrow aspirate (Perls' stain, 100x) showing increased ring sideroblasts (arrowheads). C) Next-generation sequencing pileup plot showing sequencing results for location 2q33.1 (red arrowhead) indicating the presence of an SF3B1:c1986C>A mutation (black arrowhead).

A 77-year-old woman, previously maintained on phlebotomies that had been discontinued 3 years before for a purported diagnosis of iron overload, was assessed for normocytic normochromic anemia. Her blood count showed hemoglobin of $90 \mathrm{~g} / \mathrm{L}$ (normal: 115-160), mean corpuscular volume of $93.2 \mathrm{fL}$ (normal: 79-97), erythrocyte distribution width of 28.1\% (normal: 12\%-15\%), and platelets of $422 \times 109 / \mathrm{L}$ (normal: 150-400). Iron studies showed elevated ferritin (491 $\mu \mathrm{g} / \mathrm{L}$; normal: 13-150), total iron of $14 \mu \mathrm{mol} / \mathrm{L}$ (normal: 7-26), transferrin saturation of 32\% (normal: 11\%-56\%), and unsaturated iron binding capacity of $30 \mu \mathrm{mol} / \mathrm{L}$ (normal: 19.7-66.2). The vitamin B6 level was low (<10 nmol/L; normal: 20-96). HFE C282Y, H63D, and JAK2 V617F mutations were negative. The peripheral blood smear showed marked anisopoikilocytosis (Figure 1A; Wright's stain, 40x). A 
bone marrow aspirate and biopsy showed hypercellular marrow (70\%-80\%) with moderate dyserythropoiesis, minimal dysplastic changes in other lineages, and increased ring sideroblasts (Figure 1B; Perls' stain, 100x), consistent with a myelodysplastic/ myeloproliferative neoplasm with ring sideroblasts and thrombocytosis (MDS/MPN-RS-T; WHO 2016). The karyotype was normal. Next-generation sequencing studies reported the presence of an SF3B1:c1986C>A, p.(His662GIn) mutation (Figure 1C) with a variant allele frequency of $40.5 \%$. SF3B1 mutations result in the disruption of mitochondrial iron metabolism and define a distinct subgroup of patients with myelodysplasia with a better prognosis than other subtypes.
Keywords: Myelodysplasia, Ring sideroblasts, Splicing factor $3 \mathrm{~b}$ subunit 1 (SF3B1)

Anahtar Sözcükler: Myelodisplazi, Halka sideroblast, Splicing (ucbirleştirme) faktor $3 b$ altünitesi (SF3B1)

Informed Consent: Received.

Conflict of Interest: The authors of this paper have no conflicts of interest, including specific financial interests, relationships, and/or affiliations relevant to the subject matter or materials included. 